related complex present diagnostic difficulties. The lymphadenopathy in this group may result from a treatable infection or neoplasm. To our knowledge these are the first reported cases in which ultrasound guided percutaneous biopsy has been done in such patients. We performed Tru-Cut biopsy rather than fine needle aspiration because this technique is capable of yielding a tissue specific diagnosis so that lymphomas may be characterised by their nodal architecture and immunohistological features.

Percutaneous ultrasound guided biopsy is a simple method of obtaining tissue in patients with symptoms resulting from infection with HIV. It may remove the need for laparotomy, which has many disadvantages, including the use of considerable resources to provide appropriate precautions for the larger number of staff at risk of contact with infected blood. With this technique a skilled operator can achieve millimetric precision in placing the biopsy needle. In our experience of over 200 abdominal biopsies it is a safe technique even when the needle crosses bowel or includes bowel wall in the biopsy specimen (unpublished data). Furthermore, it is cheap and puts only the operator at risk of needlestick injury.

We thank Dr S G Semple for referring patients to us.

1 Lindgren PG. Percutaneous needle biopsy. A new technique. Acta Radiol (Diagn) 1982;23:653-6. 2 Abrams DI. AIDS-related lymphadenopathy: the role of biopsy. $f$ Clin Oncol 1986;4:126-7. Godley MJ. AIDS and lymphadenopathy. Brf Surg 1986;73:170-1.

(Accepted 14 fanuary 1988)

Department of Imaging, The Middlesex Hospital, London WIN 8AA

JENNIFER J DONALD, MB, MRCP, registrar

A CORAL, MRCP, FRCR, senior registrar

P J SHORVON, MRCP, FRCR, senior registrar

W R LEES, MB, FRCR, consultan

Correspondence to: Dr Donald.

\section{Effect of stanozolol on itching in primary biliary cirrhosis}

In primary biliary cirrhosis itching can be debilitating and sometimes responds poorly to treatment. Norethandrolone, which controls itching associated with cholestasis, though it worsens jaundice, is no longer available in Great Britain. Stanozolol, a $\mathrm{C}_{17}$ substituted derivative of testosterone, causes cholestasis ${ }^{1}$ and is not recommended in patients with pre-existing liver disease. We nevertheless gave stanozolol to five patients with primary biliary cirrhosis to see whether it could be used to control itching.

\section{Case reports}

Case 1-A 57 year old woman had generalised itching that did not respond to chlorpheniramine and cholestyramine. Her liver disease was stable, but the pruritus had made her depressed. Treatment with stanozolol $5 \mathrm{mg}$ daily was started, and within the first week the itching resolved completely. It returned nine days after stanozolol was stopped because the bilirubin concentration was high but then resolved when she resumed stanozolol. After two years the bilirubin concentrations had fallen to $60 \mu \mathrm{mol} / 1$. Itching remained completely controlled. The peak concentration of bilirubin during treatment was $103 \mu \mathrm{mol} / 1$ (normal range $0-17 \mu \mathrm{mol} / \mathrm{l}$ ).

Case 2-A 53 year old woman presented with itching, malaise, and pigmentation of her skin. Results of tests of hepatic function remained stable, but itching did not respond to cholestyramine. Desperate for relief, she started stanozolol $5 \mathrm{mg}$ daily. Symptoms improved dramatically, but results of biochemical tests deteriorated: bilirubin concentration rose from 25 to $122 \mu \mathrm{mol} / \mathrm{l}$. Stanozolol was given on alternate days, but this was inadequate to control the pruritus. She restarted daily treatment and although jaundiced was free from itching.

Case 3-A 52 year old woman had pruritus that was uncontrolled by cholestyramine and started taking stanozolol $5 \mathrm{mg}$ daily. Itching improved, but six weeks later she had pain in the right hypochondrium and rapidly increasing jaundice (bilirubin concentration $300 \mu \mathrm{mol} / \mathrm{l}$ ). An endoscopic retrograde cholangiogram showed a normal biliary system. Stanozolol was stopped. The bilirubin concentration fell to values seen before she started taking stanozolol, but after 18 months' gradual deterioration she died of hepatic decompensation.

Case 4-This 78 year old woman, whose pruritus caused insomnia, developed diarrhoea while taking cholestyramine. She started stanozolol $5 \mathrm{mg}$ daily with dramatic effect, but her jaundice worsened (bilirubin concentration rose from 39 to $150 \mu \mathrm{mol} / \mathrm{l}$ ) and the drug was stopped. Two months later, when the bilirubin concentration had fallen to $68 \mu \mathrm{mol} / \mathrm{l}$, her itching was again unbearable. Stanozolol on alternate days was insufficient, and the dose was increased to $5 \mathrm{mg}$ daily despite the probability that her jaundice would worsen.

Case 5-A 47 year old woman suffered severe skin and vaginal itching despite treatment with antihistamines, cholestyramine, ultraviolet irradiation, and antifungal agents. Her general health and results of biochemical tests were stable. Close to suicide, she agreed to try stanozolol $5 \mathrm{mg}$ daily. Her pruritus resolved completely within one week. Treatment on alternate days subsequently controlled her itching. The serum bilirubin concentration had risen to $46 \mu \mathrm{mol} / \mathrm{l}$ (from $19 \mu \mathrm{mol} / \mathrm{l}$ ) after one year.

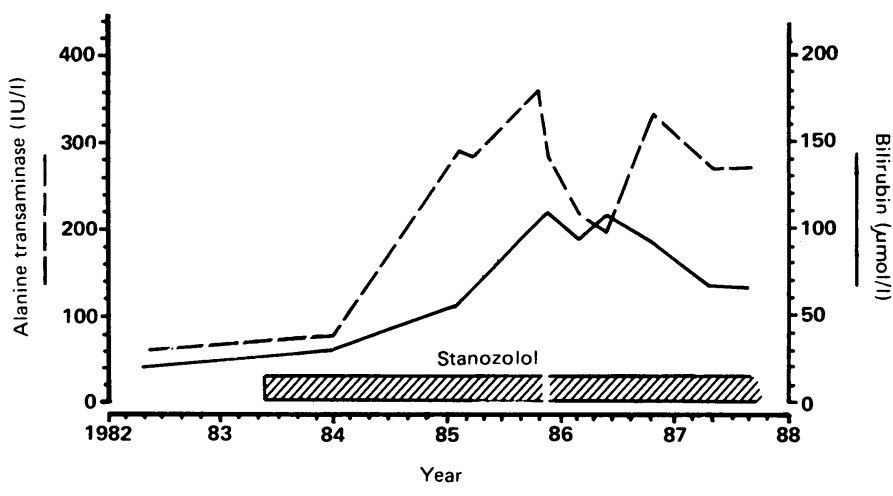

Serum bilirubin concentration and alanine transaminase activity before, during, and after treatment with stanozolol in a patient with primary biliary cirrhosis (case 1).

\section{Comment}

In most patients with primary biliary cirrhosis itching is mild and tolerable, occasionally requiring antihistamines or cholestyramine. In some patients, however, it can be severely debilitating both physically and psychologically: we treated only these patients with stanozolol. All showed dramatic resolution of pruritus within days of starting stanozolol, but one stopped the drug because of increasing jaundice.

Stanozolol increased serum bilirubin concentrations about threefold (figure), and there was a parallel rise of alanine transaminase activity. As liver biopsies were not repeated we do not know whether these increases represented histological deterioration. There was, however, no associated clinical deterioration, and serum albumin concentrations remained stable, suggesting that hepatic synthesis of albumin was unimpaired. Androgenic side effects were not noted. We commend the use of stanozolol in patients with debilitating itching associated with cholestasis for whom norethandrolone would previously have been prescribed. Before it is recommended for more general use, however, controlled study is required.

1 Everly RS, Triger DR, Milnes JP, Low-Beer TS, Williams R. Severe cholestasis associated with stanozolol. BrMed f 1987;294:612-3.

(Accepted 5 November 1987)

Department of Medicine, Queen Elizabeth Hospital, Birmingham B15 2TH R P WALT, MD, MRCP, senior lecturer

University Hospital, Nottingham NG7 2UH

T K DANESHMEND, MD, MRCP, lecturer, department of therapeutics

I W FELLOWS, MD, MRCP, senior registrar, department of medicine

P J TOGHILL, MD, FRCP, consultant physician

Correspondence to: Dr Walt.

\section{Zinc deficiency in children with dyslexia: concentrations of zinc and other minerals in sweat and hair}

Developmental dyslexia is estimated to affect about $10 \%$ of 10 year olds. Studies of mineral concentrations in hair have found that children with impaired learning and those with behaviour disorders tend to have higher concentrations of toxic metals, especially copper, lead, and cadmium. Although animal studies have shown that zinc is essential for brain development and function, ${ }^{1}$ controversy has arisen about the extent and severity of zinc deficiency in clinical practice because a simple, reliable, and sensitive test is not yet in routine use. Sweat zinc concentrations are decreased in zinc deficient states. They may be a more useful guide to clinical zinc deficiency than either hair or serum concentrations. ${ }^{2}$ Therefore we compared concentrations of minerals in sweat and hair in children with dyslexia and a control group. 